\title{
Aznalcóllar dam failure. Part 3: Dynamics of the motion
}

\author{
E. E. ALONSO* \& A. GENS*
}

\begin{abstract}
The motion of the Aznalcóllar dam slide, after the initiation of the failure, is examined in the paper. The moving mass remained essentially rigid, and Newton's second law provides the basic equation to determine the resulting dam displacement, velocity and acceleration. Resisting forces have been derived from a previous analysis of the conditions leading to failure. Pore water pressures induced by the forward motion of the dam are approximated as an undrained loading of the clay. Driving forces and their evolution in time derive from the liquefaction of tailings and the condition of constant volume of liquefied tailings pushing the moving dam forward. The stable 'cliff' left by the motion inside the tailings lagoon supports this hypothesis. The model is able to reproduce closely the distance travelled by the dam. It shows a low sensitivity with respect to reasonable changes of the main parameters. The model computes that the slide motion lasted about $15 \mathrm{~s}$, and that the maximum acceleration experienced by the dam was $0 \cdot 14 g$.
\end{abstract}

KEYWORDS: case history; clays; dams, failure; liquefaction; shear strength
Nous examinons dans cet exposé le mouvement du glissement du barrage d'Aznalcóllar au début de la rupture. La masse en mouvement est restée essentiellement rigide et la seconde loi de Newton donne l'équation élémentaire permettant de déterminer le déplacement, la vélocité et l'accélération qui en ont résulté. Les forces résistantes ont été dérivées d'une précédente analyse des conditions menant à la rupture. Les pressions d'eau interstitielle provoquées par le déplacement en avant du barrage sont représentées approximativement comme chargement non drainé de l'argile. Les forces d'entraînement et leur évolution dans le temps viennent de la liquéfaction des déchets résiduels et de la condition de volume constant des déchets résiduels liquéfiés qui poussent le barrage en avant. Le 'falaise' stable laissée par le mouvement à l'intérieur du lagon de déchets résiduels confirme cette hypothèse. Le modèle est capable de bien reproduire la distance parcourue par le barrage. Il montre une faible sensibilité aux changements raisonnables des principaux paramètres. Le modèle calcule que le mouvement de glissement a duré environ 15 secondes et que l'accélération maximum subie par le barrage a été de $0 \cdot 14 \mathrm{~g}$.

\section{INTRODUCTION}

Aznalcóllar dam, a $27 \mathrm{~m}$ high rockfill structure with an upstream clay blanket, slid forward without previous warning. The central portion of the failed dam travelled $40-50 \mathrm{~m}$ until it came to rest. As a result, millions of cubic metres of fluidised acid mine tailings were released. The dam was founded on plastic overconsolidated brittle clay. The planar basal sliding plane had the same dip as sedimentation planes of the clay. Progressive failure, acting during the long construction period of the dam, resulted in a reduction of available clay strength, eventually causing the failure. The motion of the dam beyond this instant is the subject of this paper, which is the third of three. The first two papers (Alonso \& Gens, 2006; Gens \& Alonso, 2006) describe the field observations, material properties and the (static) stability conditions of the dam.

The analysis of landslide motion after failure is seldom performed in engineering practice, although analytical and numerical procedures are available to investigate the run-out distances and velocities reached by landslides. In recent studies (Hungr, 1995; McDougall \& Hungr, 2004; Quecedo et al., 2004) the slide is idealised as a fluidised mass of soil, and the Navier-Stokes equations are integrated in depth, adapted to the curved geometry of the surface and solved for some rheological models adopted for the moving mass. In other approaches, conceived for rockslides, discrete element approaches and hybrid continuum-discontinuum models have been developed (Eberhardt et al., 2004). However, when the sliding mass maintains its initial geometry, a much

Manuscript received 8 March 2005; revised manuscript accepted 29 November 2005.

Discussion on this paper closes on 2 October 2006, for further details see $p$. ii.

* Department of Geotechnical Engineering and Geosciences. Universitat Politècnica de Catalunya, Barcelona, Spain. simpler analysis, based on rigid body motion, becomes possible. In this case, the acting and resisting forces should be precisely established during the motion. Aznalcóllar dam belongs to the class of rigid-body slides, and therefore it offers in principle an interesting opportunity to study the dynamics of the motion.

One of the field observations precisely established-the distance travelled by the dam-could not be evaluated in the static analyses reported in Gens \& Alonso (2006). Yet it is likely to offer additional information on the sliding mechanisms advanced to explain its occurrence. The situation is similar to the popular back-analysis calculation of a slide's instability. It is generally accepted that this methodology leads, under certain circumstances, to reliable estimates of strength parameters. In a similar way, a back-analysis of the known characteristics of the motion of the slide may provide reliable data on the driving and resisting forces on the slide and on the set of parameters that control these forces. The regularity of the motion, the available topographic data, the precise knowledge of pore water pressures in the foundation clay at the time of failure and the experimental effort made to characterise the clay provide a good starting point to perform an analysis of the Aznalcóllar slide movement.

The analysis also provides information on some unknown aspects of the motion, such as the velocity of the postinitiation motion and its duration. It is also expected that the dynamic analysis may help to reinforce and/or provide insight into some of the mechanisms advanced to explain the failure.

The purpose of this paper is not to provide a general procedure for the post-failure analysis of landslides but, rather, to show that a relatively simple but robust dynamic analysis of the Aznalcóllar slide can be made. The conclusions derived from this analysis offer new data on the characteristics of the slide from a different perspective and contribute to an improved understanding of the failure. 
CONCEPTUAL MODEL FOR THE SLIDING MOTION

A consideration of the most relevant geometrical and geological aspects of the slide, as described in Alonso \& Gens (2006). leads to the defined sliding model conceptualised in Fig. 1. The figure shows the position of the sliding dam at a given time $t$, when the displacement has reached a value $s$. A fundamental objective of the analysis is the determination of the variation of the displacement as a function of time: $s(t)$. The main characteristics of the proposed model are as follows.

(a) Upstream of the slide, the geometry is controlled by a vertical joint through the blue clay. This joint is parallel to the axis of the dam, and it is located below the foot of the upstream slope. The upstream scar of the slide seems to have propagated vertically upwards from the clay joint into the tailings lagoon by means of a quasivertical plane. These hypotheses correspond precisely to the set of field observations (Alonso \& Gens, 2006). The slope angle $\beta_{\text {est }}$, defined in Fig. 1, was therefore very high, presumably in the range $70-90^{\circ}$.

(b) After the failure, the exposed sub-vertical cliff of the tailings, on the upstream side of the slide, had a height of about $20 \mathrm{~m}$. It appears, therefore, that a wedge of tailings directly over the clay covering the upstream slope of the rockfill dam had slid down towards the increasingly large opening, which was formed upstream of the dam, as it moved forward. The key point is that the initial volume of the unstable wedge of tailings had remained essentially constant during the motion of the slide. Measured permeabilities of the pyritic tailings

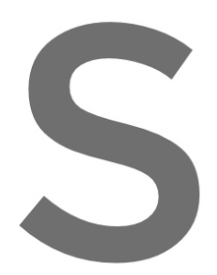
ranged between $10^{-6}$ and $10^{-7} \mathrm{~m} / \mathrm{s}$ (Alonso \& Gens,
2006), a relatively low value, which favours constant-
volume conditions during failure. The sliding wedge of
tailings probably liquefidd. Field evidence of tailings
liquefaction was also observed. The condition of
constant volume of the liquefied mass of tailings allows
the calculation of the height of tailings (given by $h$ in Fig. 1) in the basin opened upstream of the dam, as the displacement $s$ increases. It is also simple to calculate Register fakefneestat thttps ddaWWWV.Scipedia.com to of the

(c) The basal sliding plane follows the dip observed in bedding planes of the clay. The apparent dip of this plane in the direction of the motion $\left(\alpha_{\mathrm{b}}\right)$ implies that the thickness of the sliding 'slice' of Guadalquivir clay increases slightly downstream. The exit of the sliding surface was investigated by means of trenches dug after the failure. A series of highly folded layers similar to folded strata were found. This complex structure has been idealised as a passive wedge of increasing height, as the displacement of the dam increased. This wedge is resting on an inclined sliding plane, defined by the slope $\alpha_{\text {exit }}$.

(d) The critical distribution of pore water pressures against the basal sliding plane has been calculated in Gens \& Alonso (2006) for the conditions immediately before failure. This initial distribution certainly changed as the dam slid, because of the major changes in confining stresses implied by the motion of the dam. Points located on the sliding surface, downstream of the dam, experienced the sudden increase in stresses associated with the mobile weight. However, upstream of the moving dam, the sliding plane was subjected to a reduction in the height of the liquefied tailings. A 'wave' of pore water pressures, within the foundation, travelled in a downstream direction, following the moving undrained loading. Therefore normal effective stresses, and the corresponding shear strength values, changed along the basal surface as the dam moved forward. The passive wedge also experienced a change in pore pressures against its boundary, which should be considered.

All the aspects mentioned may be represented in the model presented. The analysis has been performed for a representative cross-section, in the central part of the slide. The final total displacement of the dam was not uniform in its entire length. The south-west corner of the perimeter dam remained fixed. Displacements increased gradually towards the north and reached a maximum value, close to $50 \mathrm{~m}$, in the proximity of the meander of the Agrio river. North of this

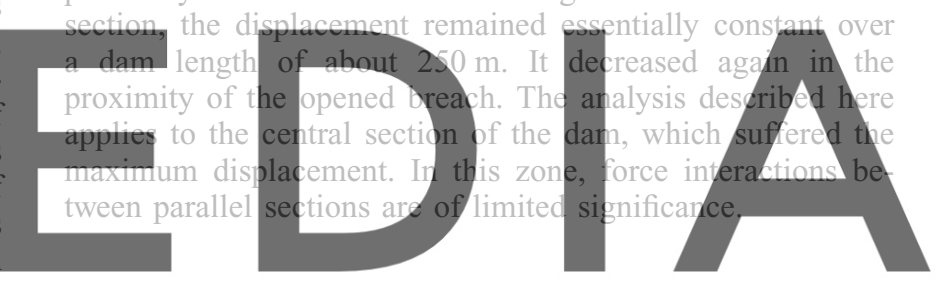

FORCES AGAINST THE SLIDING MASS
downloadcthe version without the watermark

Before liquefaction, essentially at zero displacement $(s=$

$0)$, the initial volume of tailings $V_{0}$ limited by the upstream of the dam and the subvertical rupture plane, is given by

$$
V_{0}=0.5 H\left[H \tan \left(90-\beta_{\text {est }}\right)+H / \tan \alpha\right]
$$

where $H$ is the initial depth of tailings $(27 \mathrm{~m})$ and $\alpha$ is the dam upstream slope. ( $\alpha$ is defined by a straight line approximation to a more complex profile. Its average value varies between $1(\mathrm{H}): 1 \cdot 8(\mathrm{~V})$ and $1: 1.9$ among different cross-sections: Fig. 1.) As the dam displaces, the liquefied tailings occupy the volume shown in Fig. 1, defined by the partial volumes $V_{\mathrm{a}}, V_{\mathrm{b}}$ and $V_{\mathrm{c}}$. These volumes may be easily

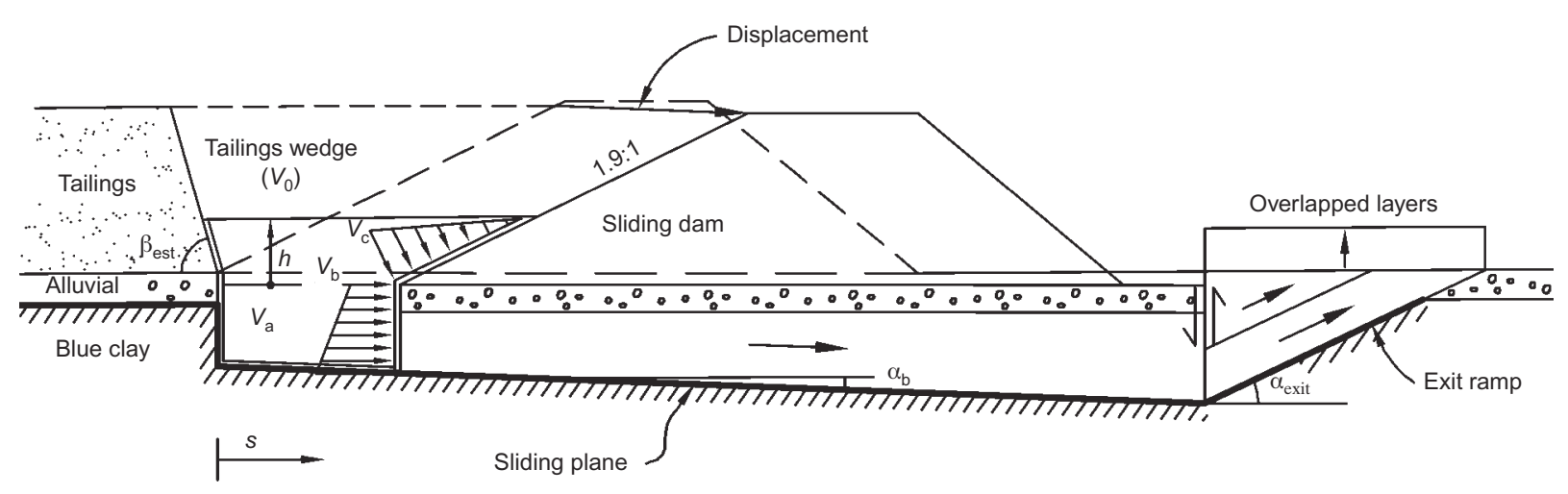

Fig. 1. Model for the motion of Aznalcóllar dam slide. 
calculated as a function of $h$ (height of tailings), the thickness of the sliding foundation soil $e_{1}$, and the dip angle of the sliding plane $\alpha_{\mathrm{b}}$.

$$
\begin{aligned}
& V_{\mathrm{a}}=\left(e_{1}-\frac{s \tan \alpha_{\mathrm{b}}}{2}\right) s \\
& V_{\mathrm{b}}=s^{2} \tan \alpha_{b}\left(1+0.95 \tan \alpha_{\mathrm{b}}\right) \\
& V_{\mathrm{c}}=(h m+f)(h-n)
\end{aligned}
$$

where

$$
\begin{aligned}
m & =\frac{1}{2}\left[1.9+\tan \left(90-\beta_{\text {est }}\right)\right] \\
f & =\frac{1}{2}\left[2+1.9 \tan \alpha_{\mathrm{b}}-\tan \alpha_{\mathrm{b}} \tan \left(90-\beta_{\text {est }}\right)\right] \\
n & =s \tan \alpha_{\mathrm{b}}
\end{aligned}
$$

The thickness $e_{1}$ is defined in terms of the thickness of the sliding foundation soil under the dam axis $e_{\mathrm{R}}$ as

$$
e_{1}=e_{\mathrm{R}}-65 \cdot 7 \tan \alpha_{\mathrm{b}}\left(e_{1} \text { and } e_{\mathrm{R}} \text { in metres }\right)
$$

because the distance from the dam axis to the upstream foot is $65.7 \mathrm{~m}$. The value of $e_{\mathrm{R}}$ is close to $14.5 \mathrm{~m}$.

The condition of constant volume of liquefied tailings

$$
V_{0}=V_{\mathrm{a}}+V_{\mathrm{b}}+V_{\mathrm{c}}
$$

allows, from equations (1), (2) and (3), the calculation of the height $h$ as a function of the displacement $s$.

Once the tailings are liquefied, the thrust against the upstream contour of the slide is calculated as a hydrostatic force (pressure diagrams are indicated horizontal component of this forc

(1)

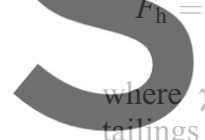
$0.5 \gamma_{\mathrm{e}}\left(h+e_{1}\right)^{2}$
$\gamma_{\mathrm{e}}$ is the specific weight of have $\gamma_{e}=31 \mathrm{kN} / \mathrm{m}$

The development of the force given by equation (5)

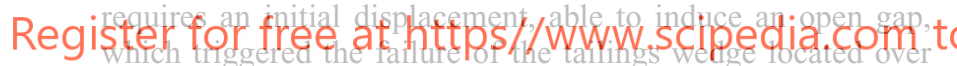
the upstream face of the dam. The opening size of this gap is unknown, and it will be considered as model parameter $\varepsilon$. For a gap depth of $12.2 \mathrm{~m}$, and the initial level of tailings in the lagoon $(h=H=27 \mathrm{~m})$ a force $F=23800 \mathrm{kN} / \mathrm{m}$ is calculated. Before liquefaction, the horizontal effective force against the dam could be defined in a simple way by an earth pressure coefficient $K$, probably intermediate between active and $K_{0}$ conditions. If the gap, which was identified as vertical fracture belonging to the main family of vertical discontinuities of the blue clay (Alonso \& Gens, 2006), was filled with saturated pyritic tailings before the initiation of the forward motion of the dam, the horizontal total force $F_{\text {hi }}$, against a vertical upstream face of the sliding body, may be approximated by a Rankine active state as

$$
F_{\mathrm{hi}}=\frac{1}{2} K_{\mathrm{a}} \gamma_{\mathrm{e}}^{\prime}\left(H+e_{1}\right)^{2}+\frac{1}{2} \gamma_{\mathrm{w}}\left(H+e_{1}\right)^{2}
$$

If

$$
K_{\mathrm{a}}=\frac{1-\sin \phi_{\text {tailings }}^{\prime}}{1+\sin \phi_{\text {tailings }}^{\prime}}=0.238 \quad\left(\text { for } \phi_{\text {tailings }}^{\prime}=38^{\circ}\right)
$$

a force $F_{\mathrm{hi}}=11370 \mathrm{kN} / \mathrm{m}$ is calculated for $e_{1}=12 \cdot 2 \mathrm{~m}$. If $K_{0}$ conditions are assumed $\left(K_{\mathrm{a}}\right.$ becomes $K_{0}$ in equation (6)) and $K_{0} \approx 0 \cdot 5, F_{\mathrm{hi}}=15600 \mathrm{kN} / \mathrm{m}$. The first term in equation (6) could even be reduced if some cementation is assumed in the tailings. Probably, the best estimation is closer to the lowest (active) value. The critical total destabilising force was thus significantly smaller than the subsequent force induced by the liquefaction of tailings. Fig. 2 is an interpretation of the evolution of the tailings thrust against the upstream face of the slide, as the displacement $s$ increases. It was found (see the section below on model calculations) that the precise values of initial and maximum values of $F_{\mathrm{hi}}$ had a very limited effect on the dynamics of the dam movement, and this finding reduces the relevance of estimating these quantities precisely. The important point, however, is that the forces against the dam increase rapidly when the tailings liquefy. This sudden increase is shown in Fig. 2. Beyond the maximum, the displacement of the dam results in a progressive fall of the level of liquefied tailings and, therefore, a reduction of the force, as also indicated in Fig. 2.

\section{Resisting forces}

A first necessary step to calculate the resistance against sliding is the estimation of pore water pressures on the basal plane. The estimated variation of pore water pressures, reported in Gens \& Alonso (2006), was simplified by means of linear variations of pore pressure head, as shown in Fig. 3 , for the initial position of the dam $(s=0)$. During its forward displacement, the dam induces an undrained loading on the sliding plane, and pore pressures in the sliding plane will be essentially controlled by the dam weight, as shown in Fig. 3.

Upstream, under the foot of the dam, it will be assumed that changes in pore water pressure are given by the current
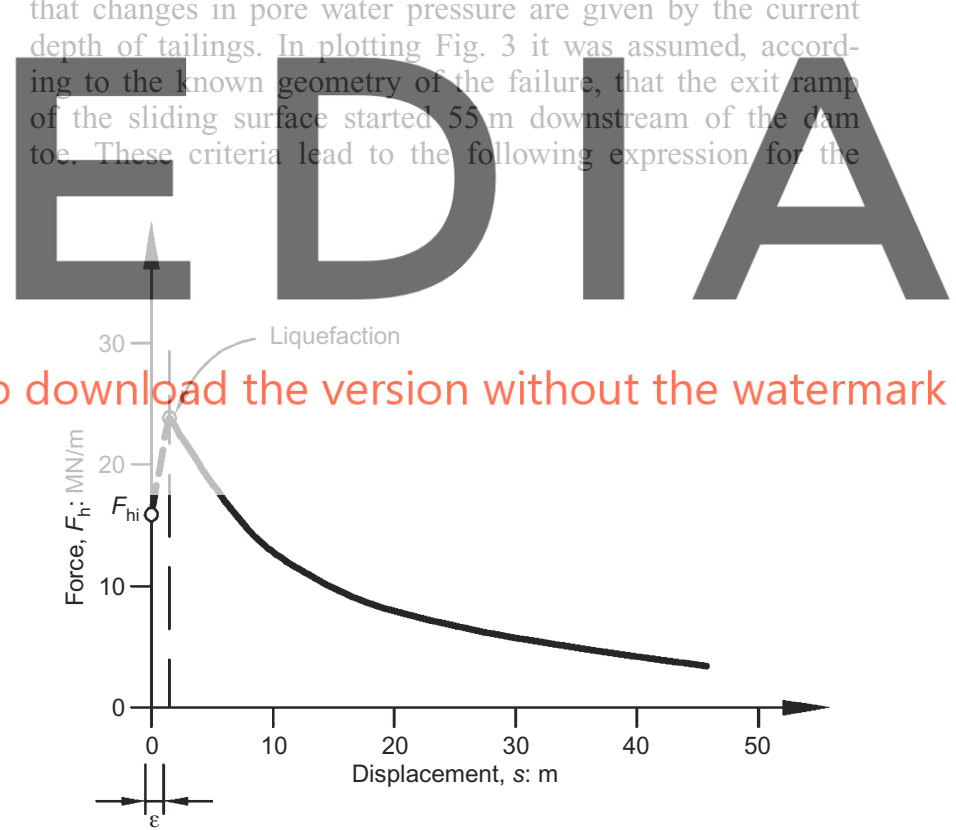

Fig. 2. Evolution of tailings thrust against moving dam and accompanying foundation soil as displacement $s$ increases

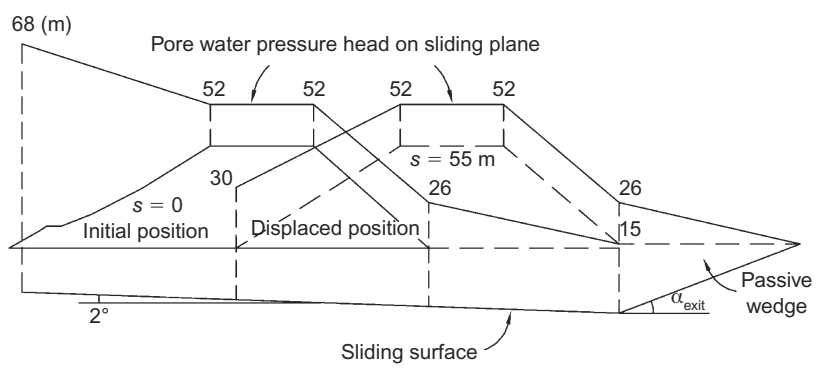

Fig. 3. Assumed distribution of pore water pressures heads (in m) under dam during sliding 
water pressure on the sliding plane in the vertical of the dam toe.

$$
u_{\mathrm{aa}}=54 \frac{h}{27}+e_{1}=2 h+e_{1}(\text { metres of water })
$$

It is then a simple matter to complete the pore pressure variations along the sliding surface as the displacements accumulates (Fig. 3).

For an arbitrary position of the displaced dam (Fig. 4), the resultant force of the water pressure against the moving upper block may be calculated as

$$
U(s)=U_{1}+U_{2}+U_{3}+U_{4}
$$

where

$$
\begin{aligned}
& U_{1}=\frac{1}{2} 53 \cdot 2 \cos ^{-1} \alpha_{\mathrm{b}}\left[\left(2 h+e_{1}\right)+37+e_{\mathrm{R}}\right] \gamma_{\mathrm{w}} \\
& U_{2}=25 \cos ^{-1} \alpha_{\mathrm{b}}\left(37+e_{\mathrm{R}}\right) \gamma_{\mathrm{w}} \\
& U_{3}=\frac{1}{2} 34 \cdot 5 \cos ^{-1} \alpha_{\mathrm{b}}\left(37+e_{\mathrm{R}}+e_{2}+10\right) \gamma_{\mathrm{w}}
\end{aligned}
$$

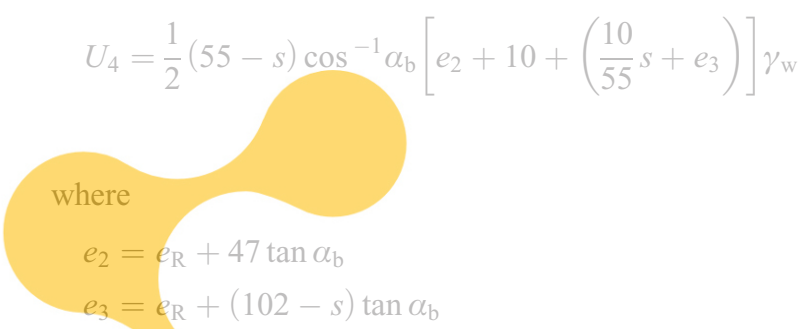

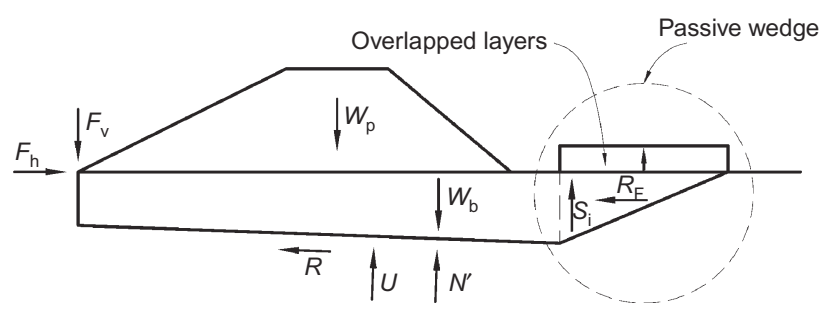

Fig. 5. Forces considered in calculation of forces resisting sliding

$$
R=N^{\prime} \tan \phi^{\prime}
$$

where $N^{\prime}$ is the normal effective force and $\phi^{\prime}$ is the effective friction angle (defined later). A purely frictional slide is considered beyond the initiation of the motion. Static instability was investigated in Gens \& Alonso (2006), and it was concluded that it corresponds to an average friction angle of $17^{\circ}$ in the base plane and a zero effective cohesion.

Global forces acting on the moving dam and foundation slab (excluding the passive wedge) are: the weight of the dam and the mobilised soil ( $W_{\mathrm{p}}$ and $W_{\mathrm{b}}$ ); the horizontal and vertical components of the liquefied tailings' thrust $\left(F_{\mathrm{h}}\right.$ and $\left.F_{\mathrm{V}}\right)$; the effect of the passive wedge $\left(R_{\mathrm{F}}\right.$ and $\left.S_{\mathrm{i}}\right)$; and the normal and shear forces on the basal plane already mentioned $\left(R, U, N^{\prime}\right)$.

Equilibrium in a vertical direction leads to

$$
N^{\prime}=\frac{F_{\mathrm{v}}+W_{\mathrm{p}}+W_{\mathrm{b}}-S_{\mathrm{i}}-U \cos \alpha_{\mathrm{b}}}{\cos \alpha_{\mathrm{b}}+\sin \alpha_{\mathrm{b}} \tan \phi^{\prime}}
$$
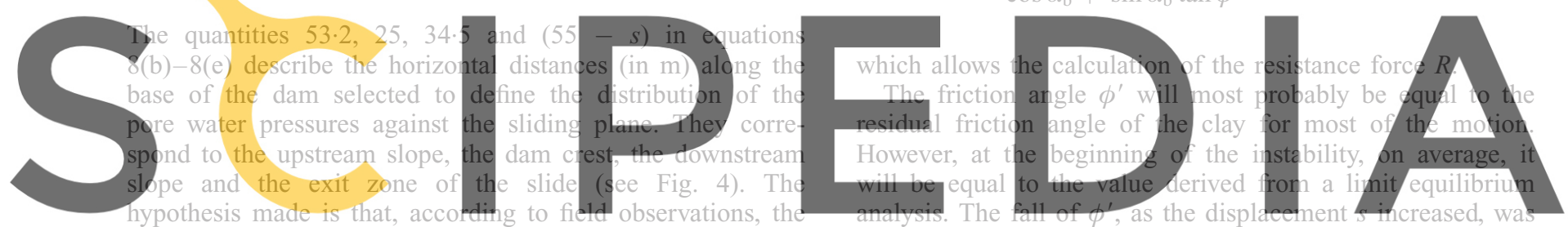

exit ramp of the failure surface started at a horizonta

certainly very rapid, given the brittle nature of the clay. The

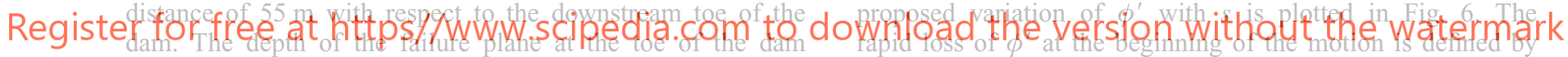

and at the beginning of the exit ramp of the failure surface

is given by equations 9(a) and 9(b) respectively.

Resisting forces can now be calculated following the scheme shown in Fig. 5. The total resisting force on the lower planar surface is expressed as

\section{a length parameter $\delta$, which will be also considered as a model parameter.}

The explicit evaluation of the resistance force $R$ through equations (10) and (11) requires finally the consideration of the passive resistance offered by the complex folded struc-

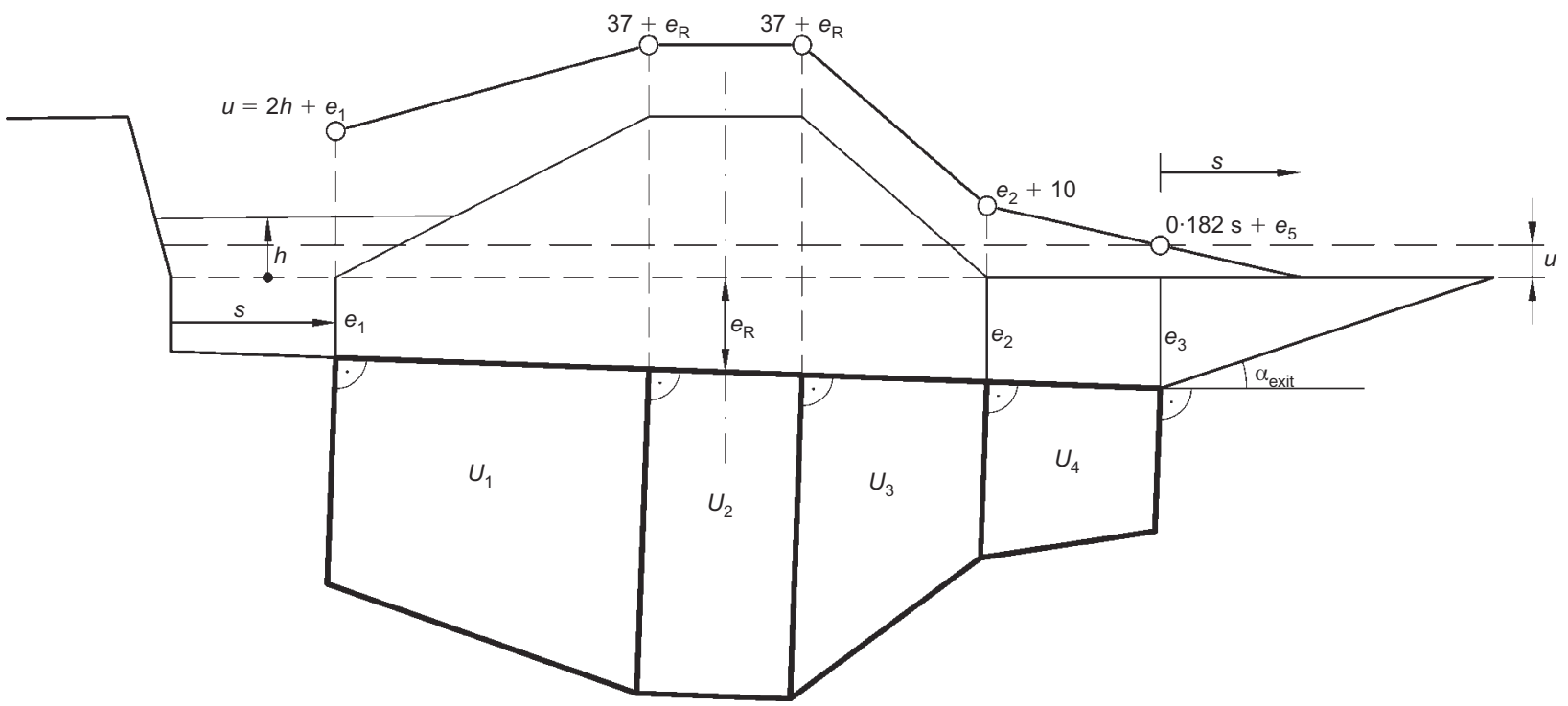

Fig. 4. Distribution of pore water pressures on sliding plane for dam displacement $s$ 


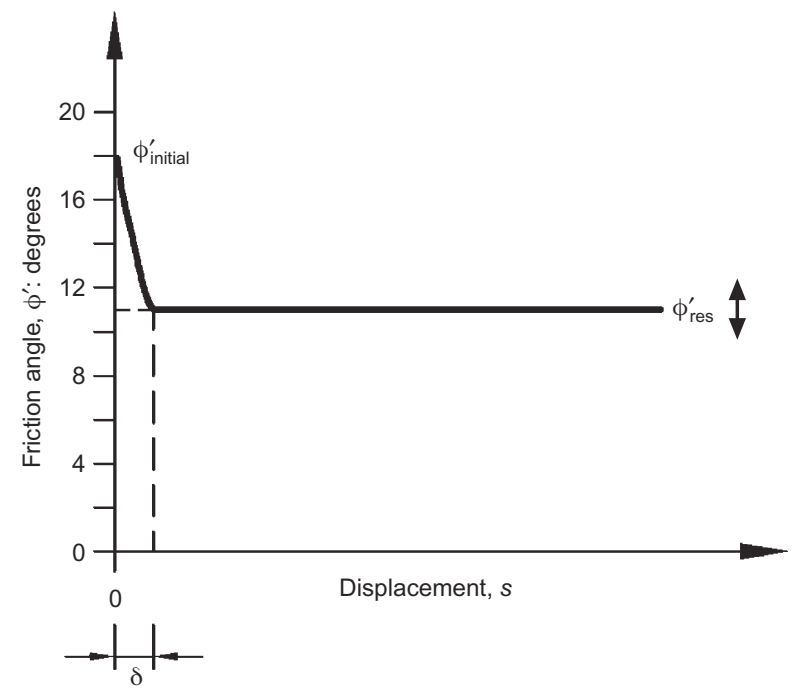

Fig. 6. Reduction of average friction angle on basal plane as a function of sliding distance $s$

ture assimilated to a passive wedge. The wedge is represented in more detail in Fig. 7. The shear resistances along the vertical and inclined (angle $\alpha_{\mathrm{b}}$ ) bounding surfaces of the wedge include clay, as well as the granular alluvium. To simplify calculations, a weighted equivalent friction angle, $\phi_{\mathrm{m}}^{\prime}$, was defined for these surfaces as follows.

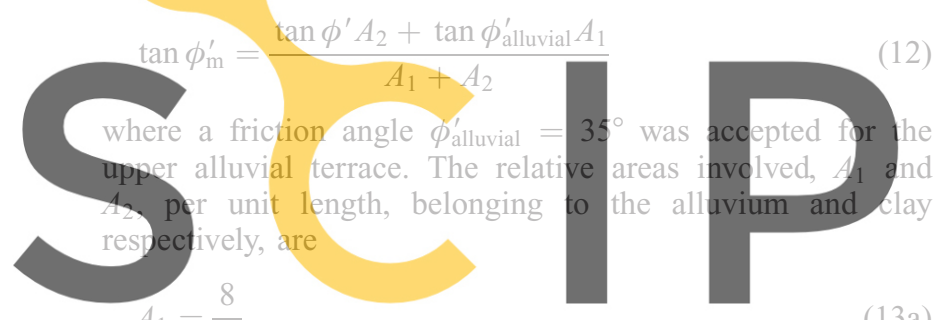

(13a)

Register for free at https//www.scipedia.ceph) to

( $e_{3}$ is expressed in metres)

Resultants of pore water pressures against the two faces of the passive wedge (Fig. 7), assuming a linear distribution, are given by

$$
\begin{aligned}
& U_{\mathrm{i}}=\frac{\gamma_{\mathrm{w}} u_{\mathrm{c}} e_{3}}{2} \\
& U_{\mathrm{f}}=\frac{u_{\mathrm{c}} e_{3} \gamma_{\mathrm{w}}}{2 \sin \alpha_{\mathrm{exit}}}
\end{aligned}
$$

where $u_{\mathrm{c}}$ is the common pressure at the lowest point, known from previous analysis.

The effective reaction force $N_{\mathrm{i}}^{\prime}$ of the passive wedge is obtained from equilibrium conditions in horizontal and vertical directions as

$$
N_{\mathrm{i}}^{\prime}=\frac{\left(W_{\mathrm{s}}+W_{\mathrm{c}}\right)\left(\tan \alpha_{\text {exit }}+\tan \phi_{\mathrm{m}}^{\prime}\right)}{1-2 \tan \phi_{\mathrm{m}}^{\prime} \tan \alpha_{\text {exit }}-\tan ^{2} \phi_{\mathrm{m}}^{\prime}}
$$

where the weight of the wedge and the accumulated soil on the surface of the wedge are given by

$$
\begin{aligned}
& W_{\mathrm{c}}=\frac{e_{3}^{2} \gamma_{\mathrm{nat}}}{2 \tan \alpha_{\text {exit }}} \\
& W_{\mathrm{s}}=\frac{e_{3} a a(s) \gamma_{\mathrm{nat}}}{\tan \alpha_{\text {exit }}}
\end{aligned}
$$

The increment of height $a a(s)$ was approximated by a linear variation between the initial value $(0)$ and the final maximum value $a a_{\max }$, which is introduced as a model parameter. Maximum elevation increases close to $8 \mathrm{~m}$ were observed in situ.

The horizontal passive effective force $N_{\mathrm{i}}^{\prime}$ changes with the inclination of the exit plane. A minimum value may be found analytically for a critical exit slope $\left(\alpha_{\text {exit }}\right)_{\text {crit }}$. For an average friction angle close to critical conditions $\left(\phi_{\mathrm{m}}^{\prime}=12^{\circ}\right)$ the following value is obtained,

$$
\left(\alpha_{\text {exit }}\right)_{\text {crit }}=17 \cdot 4^{\circ}
$$

This value is consistent with field observations, which provided values of $\alpha_{\mathrm{s}}$ close to $20^{\circ}$.

The total horizontal force resisted by the passive wedge is finally given by

$$
R_{\mathrm{f}}=N_{\mathrm{i}}^{\prime}+U_{\mathrm{i}}
$$
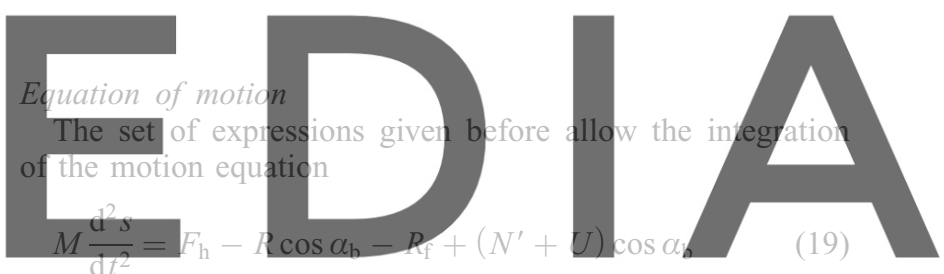

The mass $M$ was kept constant and equal to the initial value downloadhithesversiønwwithoutithe watermark and the accompanying slab of soil. Equation (19) was integrated in time by means of an explicit scheme. Accuracy of the calculation is controlied by the selected time increment, $\tau$.

\section{MODEL CALCULATIONS}

Summary of model parameters

Model parameters have been grouped in the following groups.

(a) Blue clay

$\phi_{\text {initial }}^{\prime} *$ Average initial friction angle, which ensures strict equilibrium before the failure. It was derived by limit equilibrium analysis $\left(\phi_{\text {initial }}^{\prime}=18^{\circ}\right)$.

$\phi_{\text {res }}^{\prime}$ : Residual friction angle. It is based on tests

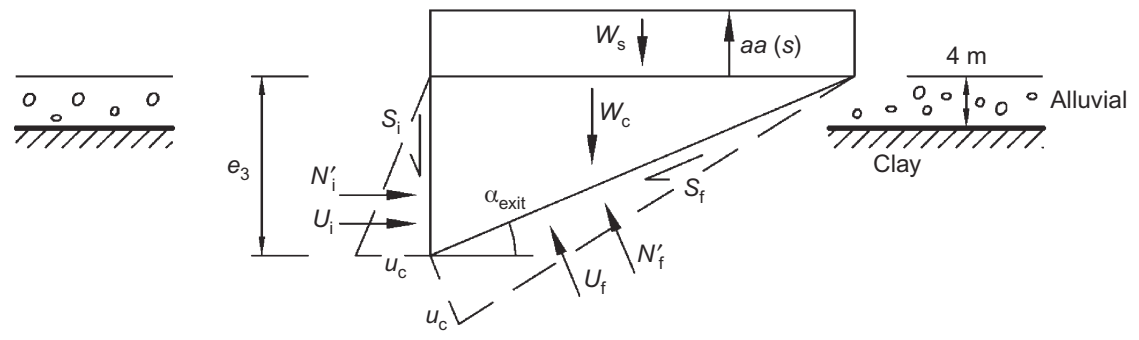

Fig. 7. Forces acting on passive wedge 
reported in Alonso \& Gens (2006). It is likely to be in the range $11-13^{\circ}$.

$\delta: *$ The relative displacement along the failure plane needed to mobilise the residual friction angle. It is probably necessary to accumulate a few decimetres to achieve residual conditions.

(b) Tailings

$\gamma_{\mathrm{e}}$ : Natural specific weight of liquefied tailings. In the southern pyrite lagoon the saturated unit weight of the deposited tailings is around $31 \mathrm{kN} / \mathrm{m}^{3}$. This is the value adopted in calculations.

$F_{\text {hi }}$ : ${ }^{*}$ Initial horizontal thrust against the dam and the accompanying slice of moving soil. It has been estimated as $15.6 \mathrm{MN} / \mathrm{m}$ under $K_{0}$ conditions and drops to $11 \cdot 3 \mathrm{MN} / \mathrm{m}$ for active conditions.

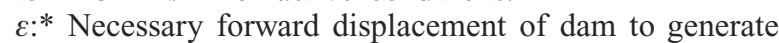
liquefaction conditions in the tailings' wedge. A value $\varepsilon=1 \mathrm{~m}$ was selected for the calculations reported below.

(c) Geometry

$\beta_{\text {est }}$ : Dip of the head scar of the slide within the tailings' deposit. Field observations indicate that it may vary between $70^{\circ}$ and $80^{\circ}$.

$e_{\mathrm{R}}$ : Depth of the failure surface under the base of the dam at the centre of the dam. It is close to $14-15 \mathrm{~m}$. $\alpha_{\mathrm{b}}$ : Apparent dip of the failure surface. Based on field observations it is estimated as $\alpha_{\mathrm{b}}=2^{\circ}$.

$a a_{\max }$ : Maximum height of accumulated soil over the passive wedge. Topographic data after the failure indicate that it reached $8 \mathrm{~m}$ in some areas. $\alpha_{\text {exit }}$ : Slope of the sliding plane under the passive wedge. Visual observations in trenches excavated at the foot of the slide indicate that $\alpha_{\mathrm{b}}$ Numerical

$\tau$ : Time step for the explict equation. Errors become

rameters marked with an asterisk (*) were found to have

very limited influence on the computed results. This was an

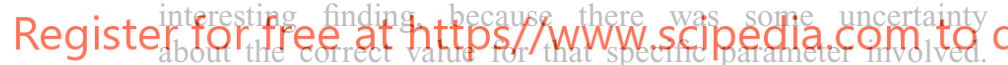

This is, in particular, the case of the two displacement parameters included in the model: $\delta$ and $\varepsilon$.

Base case

A representative base case was solved with a set of parameters that are believed to represent the actual sliding conditions: $\phi_{\text {initial }}^{\prime}=18^{\circ} ; \phi_{\text {res }}^{\prime}=11^{\circ} ; \delta=20 \mathrm{~cm} ; \gamma_{\mathrm{e}}=$ $31 \mathrm{kN} / \mathrm{m}^{3} ; F_{\mathrm{hi}}=11.3 \mathrm{MN} / \mathrm{m} ; \varepsilon=1 \mathrm{~m} ; \beta_{\mathrm{est}}=70^{\circ} ; e_{\mathrm{R}}=$ $14 \mathrm{~m} ; \alpha_{\mathrm{b}}=2^{\circ} ; a a_{\max }=8 \mathrm{~m} ; \alpha_{\text {exit }}=20^{\circ}$. Calculation starts when an initial displacement is imposed, lower than $\varepsilon$, that corresponds to a horizontal force larger than the sliding resistance. The main results of the calculation have been plotted in Figs 8 to 11 .

The distance travelled by the dam as a function of time is shown in Fig. 8. According to the model, the slide stops $14.2 \mathrm{~s}$ after the initiation of the failure, when the dam has travelled $55.2 \mathrm{~m}$. This latter figure is very similar to actual observations. The evolution of speed is shown in Fig. 9. The dam reaches a maximum velocity of $5.67 \mathrm{~m} / \mathrm{s}(20.4 \mathrm{~km} / \mathrm{h})$, $7.5 \mathrm{~s}$ after the start of the motion. The calculated acceleration is shown in Fig. 10. The dam experiences a rapid acceleration in the first few seconds after the start. The evolution of forces, plotted in Fig. 11, explains the acceleration. During the first instants of the motion, the liquefaction of tailings increases the driving force, which reaches values substantially higher than the total resistance offered by the base and the passive wedge (the evolution of both forces is

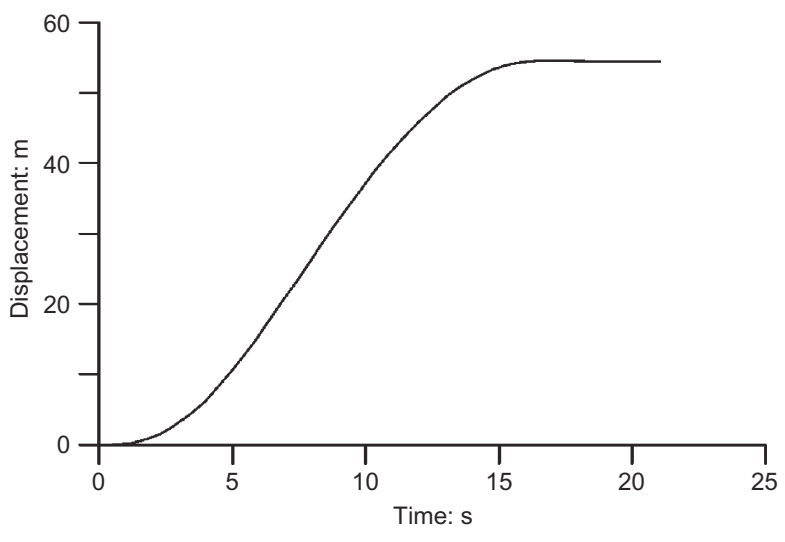

Fig. 8. Computed evolution of dam displacement
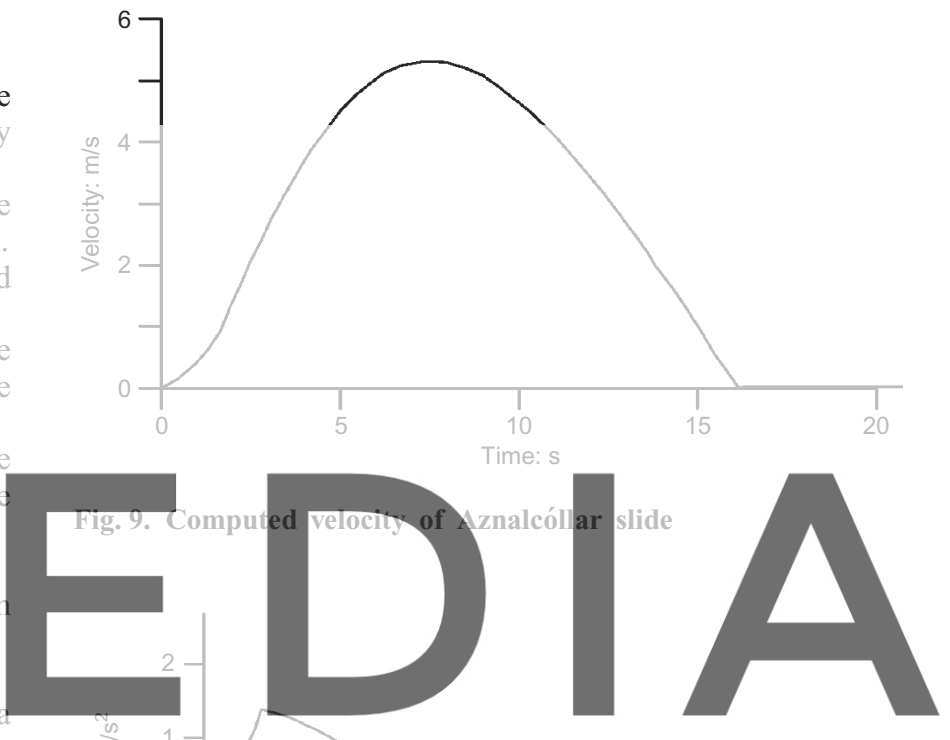

dow

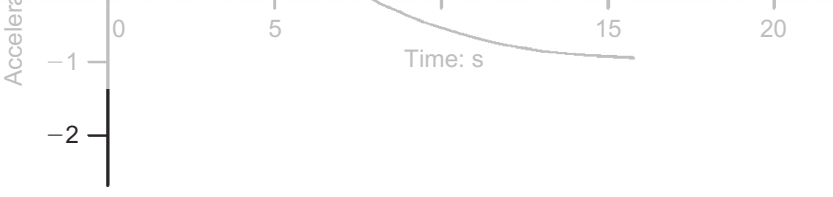

Fig. 10. Computed acceleration of Aznalcóllar slide

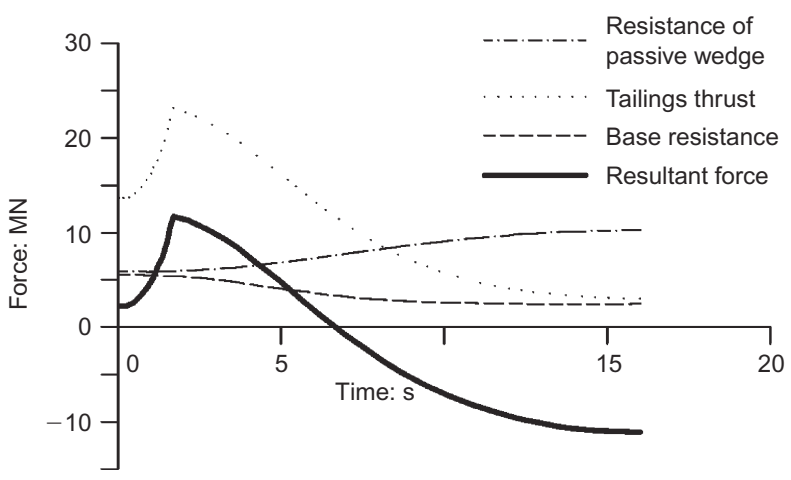

Fig. 11. Computed variation of forces against moving mass

also shown in the figure). The positive net resultant force accelerates the slide. The fall of the level of tailings at the upstream part of the slide (plotted in Fig. 12) progressively reduces the pushing force, and acceleration reduces. Total 


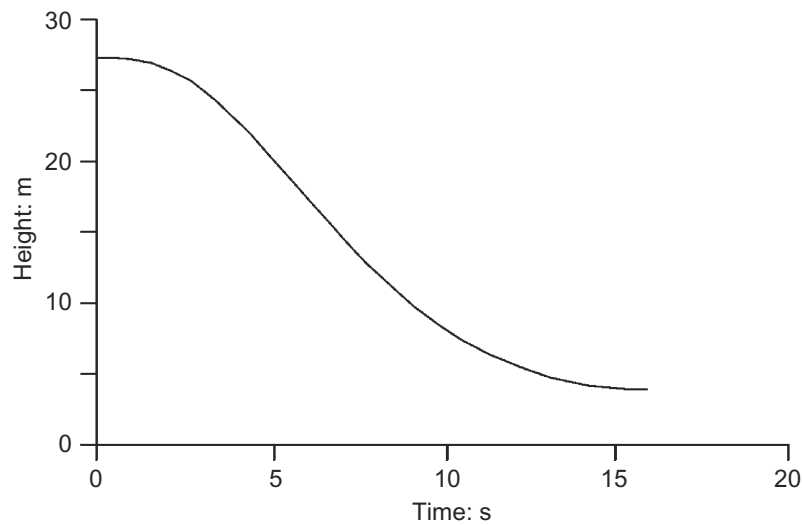

Fig. 12. Evolution of height of liquefied tailings, acting against upstream end of slide

resistance to sliding increases slightly with time. The main reason for the deceleration of the slide is therefore the continuous decrease in the driving force associated with the fall of the level of liquefied tailings.

The relevance of the stability of the tailings' cliff left by the forward motion of the dam now becomes more apparent. A large volume of liquefied tailings would have implied a longer period of acceleration, and higher velocities and dam displacements. Under these circumstances the size of the breach opened in the dam would have increased dramatically, leading to a more violent flood.

The short-term stability of a quasi-vertical slope in the mass of tailings is explained by the cementation exhruited by hem and its relatively low unloading caused by the forward stid

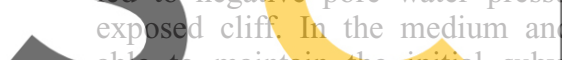
cliff. In the medium an maintain the initial sub erosion and in some cases ocal falumes led to the partial collapse of the original slope. However, the volume

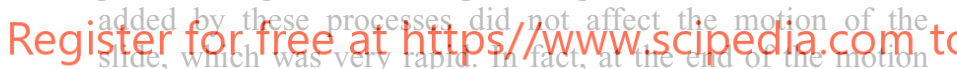
(see Fig. 11), the available resistance was much higher than the driving force. Additional sources of eroded or destabilised tailings add only marginally to the force exerted against the upper slide face. The dam breach also involved the pouring of a massive flow of tailings mud outside the dam, thus effectively controlling the level of the tailings in the large open basin upstream of the slipped dam.

The acceleration of the dam in early stages helps to explain the fall of the wedge of tailings sitting on top of the layer of red clay placed against the upstream rockfill slope. The presence of this clay, placed on top of a $1.9: 1(\mathrm{H}: \mathrm{V})$ slope, facilitated the instability of the wedge of tailings. The calculated maximum acceleration $(0 \cdot 14 g)$ is similar to the acceleration induced by an earthquake of intensity 7-8 (MKS). The calculated height of tailings in the upstream basin, when the slide stopped, is $5 \mathrm{~m}$ over the initial level of the foot of the upstream slope. The measured central profile of the slide, a few months after the failure (see Profile 4 in Fig. 15(a) of Alonso \& Gens, 2006), shows that the level of the tailings upstream of the failed dam was $7 \mathrm{~m}$ above the level of the foot of the dam. The difference, which is not considered to be very significant, is attributed to the accumulation of eroded tailings in the days following the rupture.

\section{Sensitivity analysis}

It was mentioned that the results of the analysis were not particularly affected by some of the model parameters. A relatively large uncertainty could a priori be associated with a few of them $\left(\delta, \varepsilon, F_{h i}\right)$. However, most of the model parameters were known with some confidence, although there always remains some uncertainty. It is therefore advi-

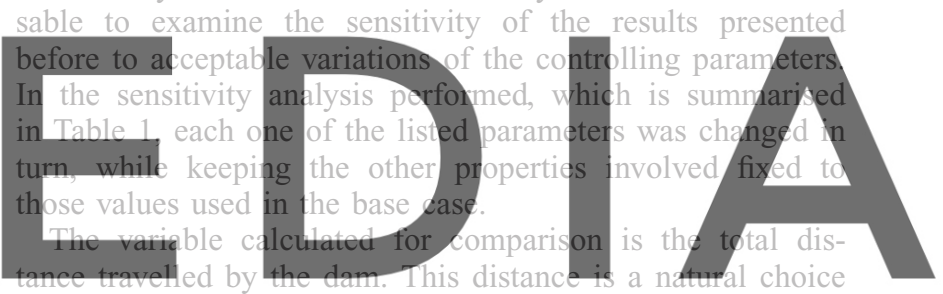
because it can be compared with the measured value in the

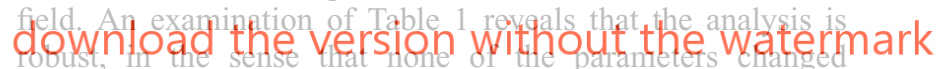
seems to have a decisive influence on the distance travelled by the dam. The values listed in Table 1 do not differ much from the actual travelled distance. This result adds confi-

Table 1. Results of sensitivity analysis in terms of distance travelled by dam

\begin{tabular}{l|c|c}
\hline Parameter/property & Value & Distance travelled: $\mathrm{m}$ \\
\hline Slope of sedimentation planes, $\alpha_{\mathrm{b}}$ : degrees & 2 & $55 \cdot 2$ \\
& 1 & $50 \cdot 5$ \\
& 0 & 46 \\
Dip of upstream scar, $\beta_{\text {est }}$ : degrees & -1 & $41 \cdot 7$ \\
& 90 & $51 \cdot 2$ \\
Residual friction angle of clay, $\phi_{\text {res }}^{\prime}$ : degrees & 10 & $47 \cdot 4$ \\
& 12 & $60 \cdot 7$ \\
Exit angle of passive wedge, $\alpha_{\text {exit }}$ : degrees & 10 & $49 \cdot 9$ \\
& 15 & $43 \cdot 7$ \\
& 25 & $51 \cdot 5$ \\
Maximum height of accumulated soil on passive & 30 & $56 \cdot 3$ \\
wedge, $a a_{\text {max }}$ m & 10 & $51 \cdot 7$ \\
Depth of sliding surface under base of centre of & 12 & $48 \cdot 7$ \\
dam, $e_{\mathrm{R}}$ : $m$. & 13 & $58 \cdot 9$ \\
Specific weight of tailings, $\gamma_{\mathrm{e}}: \mathrm{kN} / \mathrm{m}^{3}$ & 29 & $51 \cdot 8$ \\
& 30 & $50 \cdot 7$ \\
\hline
\end{tabular}


dence to the interpretation given for the observed displacement of the dam and the associated physical phenomena.

\section{CONCLUDING REMARKS}

The relatively simple model seems to capture the more significant aspects of the slide motion. The model is capable of reproducing accurately the distance travelled by the slide, providing confirmation of the selected hypothesis and model parameters. In particular, the model incorporates the estimated pore water pressures along the sliding surface and the residual friction angle of the blue clay. Both are important parameters in explaining the initiation of the failure.

The model is consistent with the liquefaction of the wedge of tailings sitting over the upstream slope of the dam. It is considered that the initiation of the failure resulted initially in a quasi-vertical gap, which induced the sliding of the wedge and its liquefaction. The conservation of the volume of liquefied tailings is probably the key assumption to explain the distance travelled by the dam. Field observations are consistent with this assumption because the upstream quasi-vertical cliff opened in the tailings' mass, as a result of the forward motion of the dam, remained essentially stable.

The analysis also provides some information on several unknown aspects of the motion. It was found that the motion was rapid, and it came to rest $15 \mathrm{~s}$ after the initiation. The calculated maximum velocity and acceleration $(20 \mathrm{~km} / \mathrm{h}$ and $0 \cdot 14 \mathrm{~g}$ respectively) provide key insights into a better understanding of the slide.

It was shown that the motion stopped because the driving

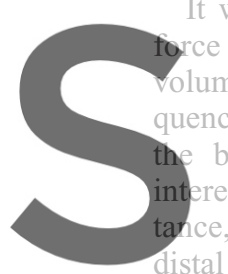
ce was reduced, owing to $t$ (n)

lume of liquefied tailings. quence of the movement of basin being opened up resting to realise that the , offered by the passive l extreme of the slide, stopping the motion.
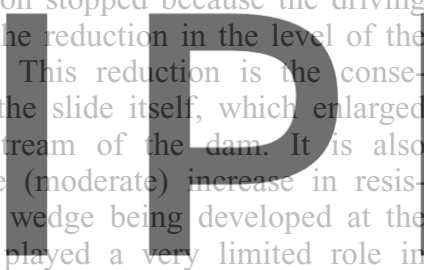

limited role is

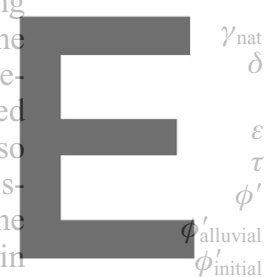

Register for free at https//www.scipedia.com to

\section{NOTATION}

$A_{1}, A_{2}$ length of segments of sliding plane of passive wedge in granular alluvium and blue clay respectively

$a a(s)$ current height of accumulated folded layers over passive wedge

$a a_{\max }$ maximum height of accumulated folded layers over passive wedge

$e_{1}$ depth of sliding plane under upstream toe of dam

$e_{2}$ depth of sliding plane under downstream toe of dam

$e_{3}$ depth of sliding plane at origin of exit ramp

$e_{\mathrm{R}} \quad$ depth of sliding plane under dam axis

$F_{\mathrm{h}}, F_{\mathrm{v}}$ horizontal and vertical components of liquefied tailings thrust against dam

$F_{\mathrm{h}_{\mathrm{i}}}$ thrust acting against sliding body in its upstream side

$H$ initial height of tailings over upstream toe of dam

$h$ current height of tailings over upstream toe of dam during sliding motion

$K$ earth pressure coefficient

$K_{\mathrm{a}}$ earth pressure coefficient for active conditions

$K_{0}$ earth pressure coefficient for at-rest conditions

$M$ mass of sliding dam and accompanying soil
$N^{\prime}$ effective normal force on sliding surface

$N_{\mathrm{i}}^{\prime}$ effective horizontal reaction force offered by passive wedge

$N_{\mathrm{f}}^{\prime}$ effective normal force against base of passive wedge

$R$ resisting force on lower planar sliding surface

$R_{\mathrm{F}} \quad\left(=N_{\mathrm{i}}^{\prime}+U_{\mathrm{i}}\right)$ horizontal resistance force of passive wedge

$s$ horizontal displacement of dam during sliding

$S_{\mathrm{f}}$ total shear sliding force at base of passive wedge

$S_{\mathrm{i}} \quad$ shear force in vertical upstream side of passive wedge

$U_{1}, U_{2}, U_{3}, U_{4}$ components of water pressure force against base sliding plane

$u_{\mathrm{aa}} \quad$ water pressure on sliding plane below dam upstream toe

$u_{\mathrm{c}}$ pore water pressure at deepest point of passive wedge

$U \quad\left(=U_{1}+U_{2}+U_{3}+U_{4}\right)$ total water pressure force against base of sliding plane

$V_{0}, V_{\mathrm{a}}, V_{\mathrm{b}}, V_{\mathrm{c}}$ total $\left(V_{0}\right)$ and partial volumes of liquefied tailings

$U_{\mathrm{f}}$ total water pressure force against base of passive wedge

$U_{i}$ total water pressure force against unstream side of passive wedge

$W_{\mathrm{b}}$ weight of mobilised soil sliding with dam

$W_{\mathrm{p}}$ height of dam upstream slope of dam dip of basal failure plane slope of basal plane of passive wedges

$\beta_{\text {est }}$ slope of cliff in tailings lagoon left by forward dam slide total and submerged unit weight of liquefied tailings

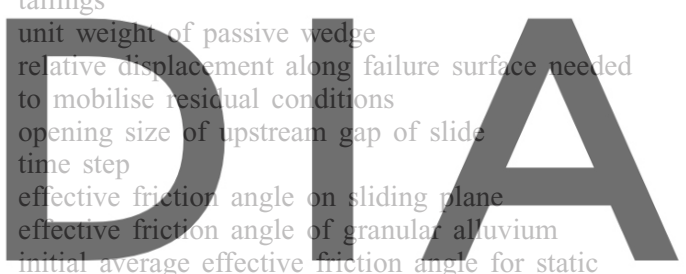

equilibrium

effective equivalent mobilised friction angle on the eidersign without the watermark residual friction angle of blue clay effective friction angle of tailings

\section{REFERENCES}

Alonso, E. E. \& Gens, A. (2006). Aznalcóllar dam failure. Part 1: Field observations and material properties. Géotechnique 56, No. 3, 165-183.

Eberhardt, E., Stead, D. \& Coggan, J. S. (2004). Numerical analysis of initiation and progressive failure in natural rock slopes: the 1991 Randa rockslide. Int. J. Rock Mech. Mining Sci. 41, No. 1, 69-87.

Gens, A. \& Alonso, E. E. (2006). Aznalcóllar dam failure. Part 2: Stability conditions. Géotechnique 56, No. 3, 185-201.

Hungr, O. (1995). A model for the runout analysis of rapid flow slides, debris flows and avalanches. Can. Geotech. J. 32, No. 4, 610-623.

McDougall, S. \& Hungr, O. (2004). A model for the analysis of rapid landslide runout motion across three-dimensional terrain. Can. Geotech. J. 41, No. 6, 1084-1097.

Quecedo, M. P., Herreros, M. I. \& Fernández Merodo, J. A. (2004). Numerical modelling of the propagation of fast landslides using the finite element method. Int. J. Numer. Methods Engng 59, No. 6, 755-794. 